\title{
The benefits of writing a Review
}

\section{Damien Hall ${ }^{1,2}$}

Published online: 16 October 2019

(C) This is a U.S. government work and not under copyright protection in the U.S.; foreign copyright protection may apply 2019

The main body of articles contained within this Special Issue review the background areas of keynote seminars presented at the $4^{\text {th }}$ Symposium on Nanoengineering for Mechanobiology (N4M) held in Genoa, Italy, in late March of 2019. The underlying themes of the N4M Symposium and this Special Issue derived from it are

(i) How mechanical environments, through the exertion of various fields and forces, determine the function and outcomes of the cells and tissues, and

(ii) Techniques and outcomes for the identification of the mechanical properties of cells and tissues, as well as the individual molecules and structures occurring within them.

The articles are written by a collection of physicists and engineers working at the biophysics/medical engineering interface. They cover the full armamentarium of micron to nanometer scale engineering, manipulation and observation methodologies (including the most modern microscopy, spectroscopy and nanoscopy techniques), this Special Issue arguably constitutes one of the most fundamental representations of

This Special Issue (Volume 11, Issue 5) highlights research presented at the "Nanoengineering for Mechanobiology" Meeting held in Camogli, Italy, March 2019. Supporting a series of substantial Reviews this Special Issue also contains a number of topical Commentaries written by some established (and just starting out) scientists in the field that provide interesting perspectives on a range of mechanobiology-related topics. After making comment on the Special Issue contents this Editorial goes on to address some broader issues that relate to the journal's progress and concludes with a description of the general benefits of writing and publishing a review article.

Damien Hall

damien.hall@nih.gov; damien.hall@protein.osaka-u.ac.jp; damienhall30@gmail.com

1 Laboratory of Biochemistry and Genetics, NIDDK, NIH, Bld. 8, Bethesda, MD 20892-0830, USA

2 Institute for Protein Research, Osaka University, 3-1- Yamada-oka, Suita, Osaka 565-0871, Japan classical physical principles applied to cell and tissue behavior published in the journal to date. I would like to congratulate the Special Issue Editors Massimo Vassalli, Marco Capitanio, Aldo Ferrari, and Boris Martinac for the interesting array of Review articles they have commissioned and for their collective efforts in keeping the Issue on schedule. A summary of the individual Reviews included within this Special Issue is provided within the main Editorial (Ferrari et al. 2019) and I refer the interested reader there for a useful precis of contents.

To provide some additional perspective on the mechanobiology field, the Special Issue Editors have commissioned a number of topical Commentaries. First amongst these is a brief look into the possible future of mechanobiology research written by a senior researcher in the field, Prof. Jochen Guck of the Max Planck Center for Physics of light (Guck 2019). Following this is a Commentary from the President of the European Society of Biomechanics (Prof. $\mathrm{M}_{\mathrm{a}}$ Angeles Peréz Anson) who has written about the work of that Society to facilitate mechanobiology research from the microscopic to macroscopic level (Pérez 2019). Next we hear from a young researcher (Assist. Prof. Robert Steward Jr.) just setting up a laboratory in the mechanobiology field (Steward 2019). Rounding out these commentaries is a piece written by the Director (Prof. Peter Kohl) and Senior Staff (Dr. Julia Verheyen and Dr. Remi Peyronnet) of the Institut für Experimentelle Kardiovaskuläre Medizin (IEKM) who provide an inside perspective on the establishment and maintenance of a dedicated Mechanobiology Institute comprising over fifty academic staff and students (Verheyen et al. 2019).

\section{Project Deal}

Moving beyond Special Issue topics, I now introduce that relate to the running of the journal. To start, I note the positive advantages soon to be provided to the journal through its scheduled participation in "Project Deal" (2019). This is an agreement between more than 700 German academic institutions (that collectively constitute the Alliance of German 
Science Organizations) and the major science publishing houses (Project Deal 2019). Its aim is to provide an openaccess reading and publishing arrangement for researchers based at the Alliance of German Science Organizations affiliated research centers. As recently outlined in a memorandum of understanding between Springer-Nature and the Project Deal parties, the benefits for readers and authors of Biophysical Reviews will be both regional and international in nature (Springer Memorandum 2019). For affiliated German-based researchers, publication within Biophysical Reviews will automatically involve an open-access arrangement with no additional open-access fee required. By guaranteeing all German-based research published within Biophysical Reviews is to be open access, Project Deal also provides significant benefit to international readers of the journal, by effectively guaranteeing access to this subset of articles to anyone with an internet connection.

\section{The Michèle Auger Award}

Readers of the journal are reminded of the upcoming deadline October $31_{\text {st }}$ for nominations for the "Michèle Auger Award for Young Scientists' Independent Research," which will be granted to a single candidate performing biophysical research, who at the time of application, is under 40 years of age. Prof. Michèle Auger was a valued Member of the Biophysical Reviews Editorial Board and her recent death was a sad loss felt by all associated with the journal. More about her life and works can be read within the online IUPAB Newsletter (IUPAB 2018). Described more completely in a prior Editorial (Hall 2019), the memorial award consists of a plaque, a free personal subscription to the journal, and an invitation to submit a single-author Review article to Biophysical Reviews. The winner's article will carry a short foreword about the life and works of Prof. Michèle Auger. Candidate nominations (either self or via direct recommendation) are requested in the form of a candidate's one page curriculum vitae, along with five original papers. Submissions may be sent by email to any of the Senior Editors of the journal (Chief Editor, Executive Editors), with the winner announced in early December.

\section{Becoming a Reviewer of Manuscripts}

One recent, and rather interesting, phenomenon is the sudden increase in direct inquiries volunteering/requesting to act as assessors of submitted review articles. While this groundswell

\footnotetext{
${ }^{1}$ Publons aims to measure one's prestige and collegiality in critiquing manuscripts through the peer review cycle.

${ }^{2}$ Particularly for those just starting out as newly minted $\mathrm{PhD}$ holders.
}

of collegiality should be applauded, I suspect that at least some part of this relatively recent upswing in desire to perform reviewing duty stems from a wish to maximize an individual's Publons' score - the new metric introduced by Clarivate Analytics (Publons 2019). ${ }^{1}$ My response to the authors of such requests ${ }^{2}$ is to suggest to the correspondent that by far the best way of being included in the Biophysical Review's Reviewer pool is to first establish an association with the journal by submitting and publishing a single-author review article. Prior to submission of a Review, inquiries should be made with the Chief Editor to discuss both the suitability of the topic and a timeframe for submission (typically 4 to 6 months from the point of official invitation). Through the act of publishing within Biophysical Reviews, each author is then included within a database that includes personal descriptions of specialist subject areas along with up to date personal contact details. Such information is consulted by the relevant Handling Editors when seeking potential assessors of a manuscript.

\section{The benefits of writing a Review}

To close out this Editorial, I would like to briefly describe the beneficial and negative aspects to keep in mind when contemplating writing a review article. On the positive side, a wellwritten review can be a benefit to both the author and others interested in the same scientific area. The benefits to self and community are three-fold

(i) Reading the literature: Without doubt there are many noble scientists who right after their morning run begin each day by summarizing the most recent pertinent literature in their field. For other less diligent scientists (myself very much included), the process of writing a review article compels the author to undertake a serious examination of the published literature. This forced confrontation aspect helps to mold the Review writing researcher into something more resembling a research scholar, i.e., one who performs original work cognizant of already published work in the field. To my mind if this was the only benefit it would indeed be sufficient.

(ii) Scouting and pedagogy: Depending on the author's/authors' style, there will be a varied mixture of teaching and reportage within each review article. Pedagogical aspects are particularly important when the author is addressing interfacial topics comprising a number of different subject areas, some of which are likely to be unfamiliar to the typical reader. This type of Review provides the author many of the same benefits as gotten from an actual teaching duty, i.e., one rapidly becomes aware of their own level of understanding when forced to teach the material to another in a formal setting. The scouting 
aspect comes into play when writing a cutting edge Review for an expert audience. In this format, rather than teaching the reading audience something, the author is instead acting in the role of forward-deployed reconnaissance scout, whose job is to report latest information about maneuvers on the research battlefront. This practiced ability to effectively condense and communicate complex information represents an amazingly useful skill — both for the author and for all scientists working within the field whom are reading the work.

(iii) Writing and synthesis: Like many activities, scientific writing, based on the collation of results and synthesis of concepts and ideas, definitely improves the more you do it. In today's modern world, many scientists may not actually write a lot of the papers in which they are listed as an author due to pressures associated with paper production or a defined system of paper production existing within the structure of the laboratory. In such circumstances, the writing of a single-author review article each 1 or 2 years can be of great benefit in the training of capable independent scientists, equipping them for an independent research career. Due to the fact that it is not entirely dependent upon the generation of results in the laboratory (as with a primary research paper), a review article provides scientists, both old and new, with a more accessible point of entry to engage the published literature and practice their skills in scientific argument and synthesizing literature results into cohesive paradigms.

Whilst the preceding points make a case for writing a review article, there are also a number of downsides. These negative aspects are again three-fold

(i) Time away from primary research: The primary role of a professional research scientist is the generation of new scientific understanding gained through the performance of experiments, with this knowledge typically packaged and presented in the form of a research paper. Such primary research papers, in which the case is made for the acceptance and meaning of new scientific results, are therefore distinct from secondary research papers, such as review articles, which discuss the collective meaning of published results from a number of primary literature sources. Career success for research-focused academics is largely correlated with the number and impact of the primary research articles they produce. Performing highlevel original research takes time and very often usable blocks of time are a researcher's most valuable item. Spending the necessary time to genuinely engage with the review writing process (and therefore accrue the benefits described above) can further diminish one's available work time to the point that the researcher's major goal of producing original knowledge, can be temporarily suspended or relegated to the second-tier priority level. Potential authors beware!

(ii) Too many reviews: One of the benefits alluded to above was that afforded to the field by a Review containing valuable teaching material and/or the latest key field specific information. However, as may have been noticed by some researchers, the total volume of scientific literature (both primary and secondary) is undergoing an explosion and we are currently at risk of being swamped with too much information. A practical manifestation of this increasing amount of content is the growing trend for Reviews to include a front section that reviews the Reviews, prior to moving onto an analysis of the primary literature. Review writers must weigh up the benefits of adding another review article to an already saturated and over-reviewed field. Of potential use to the author contemplating adding a Review to a crowded field is to first begin by writing a paragraph describing the positives and negatives of already existing review articles along with how their prospective Review will be different from the others. Arriving at an honest answer to this question should assist with the author's decision-making process.

(iii) Superficial/usual suspect reviews: Under significant work and deadline pressures, the specter of superficiality can quietly enter the room and take its spot at the authorship table. The product of this unwanted assistance is a review article which is similar in content and structure to other Reviews, with the tendency to reference a common set of articles. While not seeking to make perfect the enemy of the good, I think that these types of Reviews can be destructive for all involved for a number of reasons. With regard to the author: In producing such superficial review articles, the author(s) do not gain any of the positive benefits associated with engaging the literature nor do they gain any significant advantage associated with practice at writing and/or argument development. With regard to the field: Superficiality can inflict its damage in a number of ways. The first is by removing those direct benefits associated with high-quality pedagogy, latest information update and/or novel synthesis and presentation that are either absent or resemble efforts made in other recent review articles. The second way in which superficiality can be destructive is through the reinforcement of citation patterns. Many readers will be familiar with the existence of highly cited articles that after being given a careful read through, seem to be not entirely deserving of the citation attention paid to them. Sometimes this over-citation effect can be the result of purposeful preferential selection by so-called science citation cartels (Wallace et al. 2012; Fister et al. 2016). However, over-citation can also result from a less sinister set of intentions due to superficiality/rushing of latter 
derivative Reviews which use an earlier Review as a directive template. In today's metric-driven world, the danger is indeed extant that citation lions may sometimes emerge from indifference!

It is hoped that this somewhat wide-ranging Editorial may have provided some food for thought for readers of the journal. As the journal's reason for being is literally to both publish high-quality topical reviews and to facilitate the growth of biophysics in all areas of the world, it would be advantageous if the net result of this sojourn into Review writing imperatives has been on the whole more positive/encouraging than negative. The journal requests that interested authors discuss their ideas for a Review article with their local Editorial Board Members and/or Senior Editors of the journal prior to submission. If the topic is judged a suitable fit, they will then receive the much coveted official invitation to submit their Review article to IUPAB's Biophysical Reviews.

Acknowledgements I would like to thank Ms. Shiela Chavez and Mr. John Matthew Dela Cruz for their efforts in assembling this Special Issue. I would like to thank Ms. L. Sayuri, Ms. M. Satoko, and Ms. I. Sakura for numerous stimulating discussions on science and history during the course of writing this Editorial. I thank Prof. Wilma Olson, Prof. Cristobal dos Remedios, Dr. Reed Wickner, Dr. Herman Edskes, and Dr. Meran Lloyd-Owen for helpful comments made on an initial draft of this article. I would like to acknowledge the Institute for Protein Research at Osaka University for continuing remarkable support.

This study was financially supported by the US Government in the form of an ORISE Established Scientist Position carried out at the NIDDK. This research was supported in part by an appointment to the National Library of Medicine (NLM) Research Participation Program. This program is administered by the Oak Ridge Institute for Science and Education through an interagency agreement between the U.S. Department of Energy (DOE) and the National Library of Medicine (NLM). ORISE is managed by ORAU under DOE contract number DE-SC0014664.
All opinions expressed in this paper are the author's and do not necessarily reflect the policies and views of NLM, DOE, or ORAU/ORISE.

\section{Compliance with ethical standards}

Disclaimer The author declares no competing interests.

\section{References}

Clarivate Analytics (Publons) (2019) https://publons.com/about/home/

Ferrari A, Capitanio M, Vassalli M, Martinac B (2019) Science by the sea: how nanoengineering met mechanobiology in Camogli. Biophys Rev 11(5) Current Issue

Fister I Jr, Fister I, Perc M (2016) Toward the discovery of citation cartels in citation networks. Front Phys 4:Article 49, 1-Article 49, 5

Guck J (2019) Some thoughts on the future of cell mechanics. Biophysical Reviews 11(5) Current Issue

Hall D (2019) Biophysical reviews enters the online world, provides a focus on biophysics in Asia. Biophys Rev 11(3):1-2

IUPAB (2018) Newsletter: http://iupab.org/2018/11/06/obituarymichele-auger-former-iupab-councilor/

Pérez MA (2019) Introduction to the European Society of Biomechanics. Biophysical Reviews 11(5) Current Issue

Project Deal (2019) - https://www.projekt-deal.de/about-deal/

Springer Memorandum (2019) https://www.projekt-deal.de/springernature-news/

Steward RL Jr (2019) Advice for starting a mechanobiology lab. Biophysical Reviews 11(5) Current Issue

Verheyen J, Kohl P, Peyronnet R (2019) The Institute for Experimental Cardiovascular Medicine in Freiburg. Biophys Rev 11(5) Current Issue

Wallace ML, Larivière V, Gingras Y (2012) A small world of citations? The influence of collaboration networks on citation practices. PLoS One 7(3):e33339. 1-e33339.10

Publisher's note Springer Nature remains neutral with regard to jurisdictional claims in published maps and institutional affiliations. 